\title{
Hazards of pharmacological tests of growth hormone secretion in childhood
}

\author{
A Shah, R Stanhope, D Matthew
}

Overtreatment of hypoglycaemia after insulin or glucagon tests of growth hormone secretion may result in cerebral oedema
Endocrine and General Intensive Care Units, Hospital for Sick Children, Great Ormond Street, London WC1N 3JH A Shah, MRCP, registrar $\mathrm{R}$ Stanhope, MD, honorary consultant paediatric endocrinologist

D Matthew, FRCP, consultant respiratory paediatrician

Correspondence to: Dr R Stanhope, Medical Unit, Institute of Child Health, London WCIN IEH.

B.MF 1992;304:173-4
Children with growth hormone deficiency can now be treated with biosynthetic human growth hormone. Before treatment is started the pituitary function of the child should be investigated. This is usually done with a pharmacological test of growth hormone secretion, the commonest test being insulin induced hypoglycaemia. The results of these tests may, however, be difficult to interpret, ${ }^{2}$ especially in children with blunted responses in obesity and late prepuberty, high growth hormone concentrations in starvation, and growth hormone insufficiency in coeliac disease and psychosocial dwarfism. Results of tests of spontaneous, physiological secretion of growth hormone may explain many false impressions gained by pharmacological tests, ${ }^{3}$ although overall they may have no advantage in selecting children who would benefit from synthetic growth hormone.

Another problem with pharmacological tests is that mismanagement of hypoglycaemia may cause serious complications. We report on two children who died and one who developed neurological damage after tests of growth hormone secretion. All three were admitted to our hospital during the past three years.

\section{Case reports}

CASE 1

A $4^{1 / 2}$ year old girl was admitted to hospital for investigation of short stature (height $89.5 \mathrm{~cm}$, weight $15 \cdot 1 \mathrm{~kg}$ ). After overnight starvation she was given insulin $(0.1 \mathrm{units} / \mathrm{kg})$ intravenously and 35 minutes later developed nausea, sweating, and tachycardia and rapidly became unresponsive. Before her blood glucose concentration was measured she was given $50 \mathrm{ml}$ of $50 \%$ dextrose intravenously with minimal response, and this was followed by a further $230 \mathrm{ml}$ of $50 \%$ dextrose, $100 \mathrm{mg}$ of hydrocortisone, and $1 \mathrm{mg}$ of intramuscular glucagon. Her glucose concentration by dipstick testing was greater than $44 \mathrm{mmol} / \mathrm{l}$ one hour after she received insulin. At two hours she developed generalised convulsions, which were controlled with intravenous diazepam and phenytoin; her blood sugar concentration was raised at $130 \mathrm{mmol} / \mathrm{l}$ and plasma osmolality was $388 \mathrm{mmol} / \mathrm{kg}$; she was given three bolus doses of intravenous insulin $(0 \cdot 13 \mathrm{units} / \mathrm{kg}$ each) with minimal effect on her blood glucose concentration.

Within 10 hours her plasma osmolality had fallen to $339 \mathrm{mmol} / \mathrm{kg}$. She became hypotensive and acidotic with arterial $\mathrm{pH} 7 \cdot 02$, plasma bicarbonate concentration $15.5 \mathrm{mmol} / \mathrm{l}$ and base deficit of -16.6 . She was intubated, ventilated, and transferred to the intensive care unit at our hospital. On arrival she was comatose, with fixed dilated pupils and no brain stem reflexes. Computed tomography of the head showed appreciable cerebral oedema. An electroencephalogram was isoelectric with no definite cortical activity. She developed renal failure with anuria. Because of her cerebral oedema she was hyperventilated and fluid was restricted. Despite inotropic support she remained hypotensive with a mean blood pressure of 20-30 mm Hg. She died 24 hours after the start of the test and postmortem findings were consistent with cerebral oedema.
CASE 2

A 9 year old girl with developmental delay was admitted to our hospital for investigation of short stature (height $107 \mathrm{~cm}$, weight $20 \mathrm{~kg}$ ) and polyuria. Because of sedation for computed tomography, which indicated an absence of the septum pellucidum and therefore de Morsier's syndrome, she had a reduced energy intake before her overnight fast. Insulin $(0 \cdot 1$ units $/ \mathrm{kg})$ was given intravenously combined with thyrotrophin releasing hormone and luteinising hormone releasing hormone, and after 20 minutes her blood sugar concentration was $2.0 \mathrm{mmol} / \mathrm{l}$. Five minutes later she was drowsy and difficult to rouse and her blood glucose concentration on dipstick testing was unrecordable. She was treated with at least $100 \mathrm{ml}$ of $50 \%$ dextrose and $100 \mathrm{mg}$ of hydrocortisone intravenously with minimal clinical effect. Seventy minutes after she was given insulin her blood glucose concentration was $17 \mathrm{mmol} / \mathrm{l}$. However, she developed generalised convulsions which responded inadequately to diazepam, paraldehyde, and phenytoin. She required four bolus doses of thiopentone to stop the convulsions. She was transferred to the intensive care unit, where she required intubation and positive pressure ventilation.

Two hours after the start of the test her plasma sodium concentration was $110 \mathrm{mmol} / \mathrm{l}$, potassium concentration $2.7 \mathrm{mmol} / \mathrm{l}$, osmolality $354 \mathrm{mmol} / \mathrm{kg}$, and blood glucose concentration $95 \mathrm{mmol} / \mathrm{l}$. Further computed tomography of the head indicated a right sided subdural haematoma with a shift of the midline. Subsequent tomograms showed considerable cerebral oedema with tentorial herniation and intracerebral haemorrhages. Hyperventilation and fluid restriction were initiated to treat the cerebral oedema. Fluid balance was initially difficult because her high blood glucose concentration caused diuresis and electrolyte imbalance. Later these difficulties were compounded by diabetes insipidus, probably exaggerated by the corticosteroid drugs. She had a massive diuresis with low urinary osmolality which responded to desmopressin. She was extubated after seven days. Neurologically she recovered remarkably well and seemed to regain many of her previous skills. Seizures remained a problem and she continued to take anticonvulsant drugs. Analysis of the blood samples taken during the insulin tolerance test showed panhypopituitarism.

\section{CASE 3}

A 2 year old girl was admitted to hospital for the investigation of short stature (height $64.7 \mathrm{~cm}$, weight $6.2 \mathrm{~kg}$ ) and secondary hypothyroidism. After an overnight fast she was given glucagon $(100 \mu \mathrm{g} / \mathrm{kg})$ intramuscularly. Three hours later, after the successful completion of the test, she partially ate lunch and was awake and crying during discharge from hospital. Plasma glucose concentrations measured during the test later showed that she was hypoglycaemic with a blood glucose concentration of $0 \cdot 5-1 \mathrm{mmol} / \mathrm{l}$ from 90 to 180 minutes after receiving glucagon. At home she started vomiting and progressively became unconscious. She was taken to a local accident and 
emergency department and given external cardiac massage and intubated. Her blood glucose concentration on admission was $1 \mathrm{mmol} / \mathrm{l}$. Eventually a regular heart rate was obtained after she was given intravenous bicarbonate, adrenaline, hydrocortisone, and $2 \mathrm{ml}$ of $50 \%$ dextrose. Subsequently $20 \%$ glucose infusion was started, and although her blood glucose concentration after 40 minutes was $25 \mathrm{mmol} / \mathrm{l}$, she was given a further $5 \mathrm{ml}$ of $30 \%$ dextrose before being transferred to the intensive care unit at our hospital. On arrival she was hypotensive and poorly perfused with fixed dilated pupils and absent corneal reflexes. Her plasma sodium and potassium concentrations were normal, but her plasma osmolality was $291 \mathrm{mmol} / \mathrm{kg}$ and blood sugar concentration $17 \cdot 1 \mathrm{mmol} / \mathrm{l}$. Serial electroencephalograms showed total electrocerebral inactivity, suggesting irreversible loss of cortical function. She had no brain stem reflexes. Brain stem death was diagnosed and intensive care support withdrawn. Postmortem examination showed that her pituitary gland was very small and her thyroid gland atrophic. Examination of the base of the brain showed evidence of cerebellar coning. The endocrine results were consistent with deficiencies of thyrotrophin stimulating hormone and growth hormone. Cortisol secretion was normal.

\section{Discussion}

Of the various pharmacological tests of growth hormone secretion available, insulin induced hypoglycaemia probably has the greatest potential for inducing neurological sequelae. However, this test has the advantage of assessing reserves of adrenocorticotrophic hormone. In children suspected of hypopituitarism it is prudent to use only half the usual dose of insulin.' In case 2 the child was suspected to have hypopituitarism but was given a full dose of insulin. Tests of insulin induced hypoglycaemia are not usually recommended in children under 5 years. Glucagon may be used to stimulate growth hormone secretion, as in case 3, which additionally allows glucocorticoid secretion to be assessed and is potentially safer if intravenous access is temporarily lost during the test. Excessively prolonged fasting before the test may diminish hepatic glycogen stores and contribute to an excessive hypoglycaemic response. ${ }^{5}$ In case 3 rebound hypoglycaemia after glucagon was given was probably accentuated by the prolonged fast and vomiting. In two cases the investigations were done in specialised endocrine units and yet the children developed serious complications, highlighting the risks of these procedures. These risks must be increased when the tests are done outside specialist units. No child should be allowed home until he or she has both eaten and retained a full meal under ward supervision.

In cases 1 and 2 it was probably not the hypoglycaemia but the subsequent management that caused the illness and death. A small quantity of glucose $(2 \mathrm{ml} / \mathrm{kg}$ of $10 \%$ dextrose $)$ and hydrocortisone $(100 \mathrm{mg})$ should be given intravenously and the clinical effect observed (box). If the level of consciousness does not improve within 4-5 minutes a rapid test of blood sugar should be performed in the opposite arm to the infusion as there may be an alternative cause of unconsciousness, such as a postictal state. Dipstick measurements of blood sugar are accurate for these purposes. ${ }^{6}$ It is important to continue taking blood samples as this may be of later clinical use. Hyperosmolar coma is rare in childhood. ${ }^{78}$

In cases 1 and 2 and during the latter part of the management of case 3, excessive quantities of hyperosmolar dextrose, and not hypoglycaemia, caused cerebral oedema. Glucose concentrations and osmolality fall faster in the plasma than in the brain, which results in a shift of water into the brain tissue.
Emergency management of hypoglycaemia after tests of growth hormone secretion

1 Give glucose intravenously $200 \mathrm{mg} / \mathrm{kg} \quad(10 \%$ dextrose, $2 \mathrm{ml} / \mathrm{kg}$ ) over three minutes

2 Continue with glucose infusion intravenously at a rate of $10 \mathrm{mg} / \mathrm{kg} / \mathrm{min}$

3 Remeasure glucose concentration by dipstick after 4-5 minutes and adjust glucose infusion to maintain blood glucose at $5-8 \mathrm{mmol} / \mathrm{l}$ and no higher

4 Do not give glucagon unless venous access is lost

5 Give $100 \mathrm{mg}$ hydrocortisone intravenously if hypopituitarism is suspected

6 If there is no improvement in the state of consciousness after normal glucose concentration is restored an alternative explanation should be sought

Children with hyperosmolality (serum osmolality $>350 \mathrm{mmol} / \mathrm{kg}$ ) who present in coma (Glasgow coma scale $<7$ ) cannot adequately protect their airways and should be intubated immediately; monitoring of intracranial pressure is essential. ${ }^{9}$ During a pharmacological test of growth hormone secretion, $50 \%$ dextrose solutions should not be present with the resuscitation equipment. The speed of transfer to an intensive care unit may be important as the only survivor did not require transfer to another hospital for intensive care.

Should we rely less on pharmacological tests in assessing children for treatment with growth hormone? Perhaps more worrying is the use of such tests for the assessment of short normal children before growth hormone treatment is tried. The selection of patients and dose of growth hormone to be used should not be determined by growth hormone response to a pharmacological test but by the growth rate before treatment and the condition being treated, ${ }^{10}$ as occurs in countries such as Australia. Perhaps we should be more selective about the use of tests of pharmacological growth hormone secretion; certainly they are required to assess reserves of adrenocorticotrophic hormone but have limited application in discriminating which children respond to growth hormone treatment. An appreciation of the course of action to be taken by junior doctors during the management of severe hypoglycaemia, and the probable sequelae of excessive administration of hyperosmolar dextrose solutions, may lead to a lower incidence of the development of cerebral oedema. During pharmacological tests of growth hormone secretion greater vigilance and improved resuscitation techniques need to be entertained if such tragedies are to be avoided in the future.

This manuscript was typed with financial assistance from Serono UK. We thank Dr J V Leonard, reader in child health at the Institute of Child Health, for his advice on the emergency management of hypoglycaemia.

1 Hughes IA. Handhook of endocrine tests in childhood. Bristol: Wright, 1986 2 Brook CGD, Hindmarsh PC. Tests for growth hormone secretion. Arch Dis Child 1991;66:85-7.

3 Spiliotis BE, August GP, Hung W, Sonis W, Mendelson W, Bercu BB. Growth hormone neurosecretory dysfunction: a treatable cause of short stature. FAMA 1984:251:2223-30.

4 Rose SR, Ross JL, Uriarte M, Barnes KM, Cassorla FG, Cutler GB. The advantage of measuring stimulated as compared with spontaneous growth hormone levels in the diagnosis of growth hormone deficiency. $N$ Engl $\mathrm{F} \mathrm{Med}$ hormone levels in $1988 ; 319: 201-7$.

5 Kelnar CJH. Hypoglvcaemia in children undergoing adenotonsillectomy. BMF 1976; ; $751-2$.

6 Frantz ID, Medina G, Taeusch HW. Correlation of Dextrostix values with true glucose in the range less than $50 \mathrm{mg} / \mathrm{dl}$. F Pediatr 1975;87:417-20.

7 Freidenberg GR, Kosnik EJ, Sotos JP. Hyperglycaemic coma after suprasella surgery. N Engl F Med 1980;303:863.

8 Hoffman WH. Hyperglycaemic hyperosmolar non-ketotic coma in a non diabetic child. Diabetologia 1983;25:531.

9 Tasker RC, Matthew DJ, Kendall B. Computed tomography in the assessment of raised intracranial pressure in non-traumatic coma. Neuropediatric 1990;21:91-4.

10 Darendeliler F, Hindmarsh PC, Brook CGD. Dose-response curves for treatment with biosynthetic growth hormone. $\mathcal{F}$ Endocrinol 1990;125:311-6.

(Accepted 27 Nozember 199I) 